\title{
P26 Ascending Aorta Longitudinal Strain is not Altered in Bicuspid Aortic Valve Patients
}

\author{
Andrea Guala ${ }^{1}$, Lydia Dux-Santoy ${ }^{1}$, Gisela Teixido-Tura ${ }^{2}$, Aroa Ruiz-Muñoz ${ }^{1}$, Laura Madrenas ${ }^{1}$, Minerva Gandara ${ }^{1}$, \\ Augusto Sao-Aviles ${ }^{1}$, Filipa Valente ${ }^{2}$, Laura Galian-Gay², Laura Gutierrez ${ }^{2}$, Teresa Gonzalez-Alujas ${ }^{2}$, Ignacio Ferreira ${ }^{2}$, \\ Arturo Evangelista ${ }^{1}$, Jose Rodriguez-Palomares ${ }^{2}$
}

${ }^{1}$ Vall d'Hebron Institute of Research, Barcelona, Spain

${ }^{2}$ Department of Cardiology, Vall d'Hebron Hospital, Barcelona, Spain

\section{ABSTRACT}

Background: Impaired ascending aorta (AAo) longitudinal strain, a marker of AAo deformation due to aorto-ventricular mechanical interaction, is related to progressive dilation and aortic events in Marfan syndrome [1]. Whether the high prevalence of dilation in bicuspid aortic valve (BAV) is due to intrinsically-altered aortic wall properties [2] or hemodynamic [3] is widelydiscussed [4]. Whether AAo longitudinal strain is altered in BAV patients has never been assessed.

Methods: One-hundred five BAV patients, 47 patients with AAo dilation and tricuspid aortic valve (TAV) and 31 healthy volunteers, free from previous cardiac/aortic surgery, dissection and moderate/severe valvular disease had cine MR images to compute AAo longitudinal strain [1].

Results: Compared to healthy volunteers, the 25 non-dilated $(z$-score $<2)$ BAV patients were older $(p<0.001)$, had higher systolic blood pressure (SBP, $p=0.001$ ), clinically-meaningless (BAV $z$-score $=0.74 \pm 1.1$ ) larger AAo diameter $(p<0.001)$ and similar diastolic blood pressure (DBP), BSA, stroke volume and heart rate. AAo longitudinal strain was lower in non-dilated BAV compared to healthy volunteers $(13.7$ vs $10.3 \%, p=0.008)$ but this difference was not significant after correction for age. Compared to dilated TAV, dilated BAV patients were younger $(p<0.001)$, had lower BSA $(p=0.010)$ and AAo diameter $(p=0.003)$, higher DBP $(p=0.032)$ and similar SBP, stroke volume and heart rate. AAo longitudinal strain was higher in dilated BAV compared to dilated TAV $(10$ vs $7.2 \%, p<0.001)$ but this difference was not significant after correction for age, BSA and DBP

Conclusion: AAo longitudinal strain is similar in BAV and TAV matched for aortic dilation.

\section{REFERENCES}

[1] Guala A, Teixidó-Tura G, Rodríguez-Palomares J, Ruiz-Muñoz A, Dux-Santoy L, Villalva N, et al. Proximal aorta longitudinal strain predicts aortic root dilation rate and aortic events in Marfan syndrome. Eur Heart J 2019;40:2047-55.

[2] Guala A, Rodríguez-Palomares J, Dux-Santoy L, Teixido-Tura G, Maldonado G, Galian L, et al. Influence of aortic dilation on the regional aortic stiffness of bicuspid aortic valve assessed by 4-dimensional flow cardiac magnetic resonance: comparison with Marfan Syndrome and degenerative aortic aneurysm. JACC Cardiovasc Imaging 2019;12:1020-9.

[3] Rodríguez-Palomares JF, Dux-Santoy L, Guala A, Kale R, Maldonado G, Teixido-Tura G, et al. Aortic flow patterns and wall shear stress maps by 4D-flow cardiovascular magnetic resonance in the assessment of aortic dilatation in bicuspid aortic valve disease. J Cardiovasc Magn Reson 2018;20:28.

[4] Girdauskas E, Borger MA, Secknus MA, Girdauskas G, Kuntze T. Is aortopathy in bicuspid aortic valve disease a congenital defect or a result of abnormal hemodynamics? A critical reappraisal of a one-sided argument. European Journal of Cardiothoracic Surgery 2011;39:809-14.

(c) 2019 Association for Research into Arterial Structure and Physiology. Publishing services by Atlantis Press International B.V. This is an open access article distributed under the CC BY-NC 4.0 license (http://creativecommons.org/licenses/by-nc/4.0/). 